\title{
The Art of Chain-Scission Creativity as a Business Opportunity at Kindergarten
}

\author{
Farida Mayar, Dadan Suryana, Eko Purnomo, and M. Nasrul Kamal \\ Early Chilhood Education Department, Padang State University, Padang, indonesia, mayarfarida@gmail.com \\ Early Chilhood Education Department, Padang State University, Padang, indonesia, dadan.suryana@yahoo.com \\ Early Chilhood Education Department, Padang State University, Padang, indonesia, ekopurnomo@gmail.com \\ Early Chilhood Education Department, Padang State University, Padang, indonesia, 2lamaknyo@gmail.com
}

\begin{abstract}
This service aims to train Anugrah Sayang Ibu Kindergarten teachers in Kampung Jua, Sungai Limau District. The title of this service is Chain-Scission Art Creativity As A Business Opportunity In The Kindergarten Anugrah Sayang Ibu In Kampuang Jua, Sungai Limau, Padang Pariaman Districts. Previously, the trainer had not seen that chain cutouts had never gained any knowledge of chain cutouts so far. Therefore, the trainer train the teachers so that the teachers can develop the chain-scission creativity that will be taught to kindergarten children and also to be able to be an entrepreneur for teachers to make a beautiful art. From the results obtained from this service, the teacher is interested and enthusiastic. After getting the training the participants who were kindergarten children tried to take part in the training ranging from various kinds of paper, knowing to combine the colors of objects with background colors, how to draw objects they liked and then cut out on paper folds, they were very happy doing chain editing activities as new entrepreneurial opportunities, learning materials in kindergarten.
\end{abstract}

Keywords: Business Opportunity, Creativity, Scission

\section{INTRODUCTION}

This service is based on the fact that the teachers never received any art knowledge about chain scission skills in the Sungai Limau, Anugrah Sayang's Kindergartens is located in Kampung Jua, Sungai Limau Sub-District, Padang Pariaman District, West Sumatra. The distance between this area and the subdistrict capital is approximately $57 \mathrm{~km}$, the administrative capital is Padang Pariaman Regency and the distance of the City of West Sumatra Province is approximately $67 \mathrm{~km}$.

Education continues from an early age until the end of life. Early developmental periods are very important in human life. During this period all aspects of human development are formed, the development in the left hemisphere brain must be balanced in the right hemisphere of the brain because the right hemisphere of the brain is artistic creativity. While aspects of development in early childhood that must be developed in moral and religious values, social and independence, cognitive, language, motoric, and art.

According to law number 20 of 2013 concerning the National Education system article 1 paragraph 14 that early childhood education is education that provides education services to early age in the range of ages from birth to six years. The education must be able to provide professional services to early childhood. In order to lay the foundation towards the development of attitudes, knowledge and skills so that young children are able to adjust to the environment and prepare themselves to enter further education. In this golden age a lot of potential that must be developed. This potential must be facilitated properly in order to develop optimally. One of the facilities that can develop children's potential is a sense of art. Kindergarten (TK) is a form of early childhood education which carries out an education program for early childhood which is very sensitive which is very important for children who are able to facilitate children in their growth and development, namely education and learning according to their age. Children's needs and interests. Education in kindergarten is one form of education that is very important to develop personalities and prepare them to enter the next level of education. Kindergarten education is a bridge between the informal family environment and the wider community, namely elementary schools and other environments. In kindergarten all specs of child development will be well developed with the stimuli needed by children.

One aspect of development developed in kindergarten is the aspect of artistic taste (visual art). Basically, the ability of art becomes very important in improving children's development. Art developers need to be introduced to children from an early age. Therefore, educators and parents can introduce it through a variety of simple art or through objects that have an environment around us that can be used to train children in developing fine arts. 
Fine art is divided into two, namely art in the form of two dimensions and three dimensions. art is closely related to beauty, such as drawing, printing, meronce, forming, folding, sticking, cutting in a variety of creativity.

So to develop the ability of art in children should be done through fun activities. Based on the results of several observations in kindergarten it can still be seen that children's development is not optimal, problems that arise among other things: children are more directed at reading, writing and arithmetic. Lack of development of children's fine arts abilities such as: children lack creativity in processing materials to become something, not in the form of fine arts, teachers give more examples on the board. The lack of variety of teacher activities to develop children's fine arts skills in kindergarten. more specifically, chain editing has not yet been carried out in the Anugrah Sayang Ibu Kindergarten.

Based on the phenomena that occur in the field observed, it is necessary to have an effort made to assist children in developing fine arts, one of which is the New Entrepreneurial Opportunity in Creativity of ChainsScission in Anugrah Sayang Ibu Kindergarten, Padang Pariaman, West Sumatra. In this case utilizing a cut is one of the activities that can develop creativity because the chain cutouts are related to the fine arts of creativity. The problem of partners in kindergarten teachers and children has the potential for creativity in Kampung Jua Sungai Limau based on observations:

1. Not yet able to understand the processing and technique of making art objects to be able to develop creativity.

2. Not yet able to apply to edit various processed techniques of imagination and imagination contained in the right hemisphere of the brain. So that this editing activity not only creates beautiful objects also for learning needs, but this chainediting work is also beautiful which has artistic value.

The service done was making chain-scission to make a work of art, for teachers and other communities can be used as an entrepreneurial opportunity to produce an agency such as the symbol of the BKKBN, Yakult Promotion. Like the picture below.

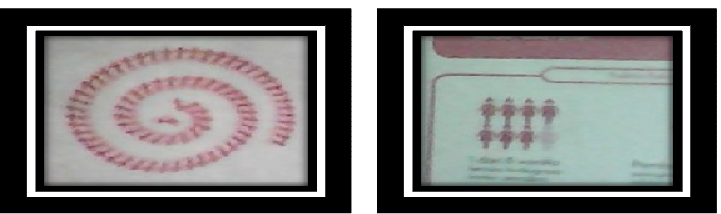

Figure 1. Example Of An Entrepreneurial Opportunity The Form Of A Chain Cutout Is The BKKBN Promotion Of The Upper Left While The Upper Right Is The Promotion Of Yakult About Health.

For early childhood chain-scission is a stimulus that make the child's fingers will become flexible, about the art of children can imagine what shape will be made so that the child is rich in his imagination. One of the characteristics of early childhood is children with imagination. Therefore, this dedication is to develop children's motor skills through chain editing provided to kindergarten teachers.

The role of the teacher as a planner in the development of art is that the teacher plans an art development activity that will be carried out with students. The first role of developing ideas and ideas is continued with application, which is practicing the imagined imagination. Therefore, the role of kindergarten teachers as educators is also the development of papers that have been cut only in ordinary form. So with a chain cut on the teacher it can be applied to children in order to be creative in fine arts and develop fine motor skills and be able to be an entrepreneur for the future children and teachers. The school itself can be decorated in the walls of the Kindergarten school into an aesthetic school.

This training can be achieved through activities that provide opportunities for children to develop talents and experiment so as to generate ideas and ideas of imagination, independence and creativity of children. Creativity is an ability to solve problems that give individuals the opportunity to create original ideas / adaptive functions of their full use for development (Widyatun, 1999).

In line with the above creativity is the ability to determine new bonding, see the subject from a new perspective, and determine new combinations of two or concepts that have been imprinted in the mind (James R. Evan, 1994).

Then creativity is an ability to think or take action aimed at finding solutions to a condition or problem intelligently, different ( out of the box), not generally original, and bringing the right and beneficial results in terms of being useful for the teacher, the child to be able to act entrepreneurship with chain cutouts.

An innovator is a human ability to use the mind and resources around it to produce an entirely new original work that is beneficial to many people. Based on the description above, it can be concluded that, being creative and innovative is really necessary in the daily life of entrepreneurship, it is demanded to have an innovative creative soul because both will determine the results of business.

Material from paper can increase the intelligence and creativity of teachers, in the development of fine arts for Taman Kanka-kanka children. each teacher should provide stimulation to develop children's fine arts and creativity. The level of development achievement in the fine arts can be related to the field of fine motor development. The child needs the teacher to practice the ability to make movements using the right fingers and wrists in a coordinated manner.

The ability to think precisely and regularly in children's imagination so as to produce a beautiful work full of emotional feelings that please. The ability to feel and train for patience in this matter includes the characteristics that should be fostered as early as possible 
in Kanka-kindergarten children. while the ability to produce ideas and ideas needs to be fostered and directed in context. Then the teacher visualizes the ability of the eye to capture the shapes and colors of objects. Teachers as instructors need to provide complete learning media to develop creativity, children will be very happy and like to imagine, besides the teacher also likes coloring, drawing, and chain editing activities have not been implemented, in terms of chain editing makes us practically work with the same object.

\section{IMPLEMENTATION METHOD}

The method offered to solve the problem is by demonstration, lecture, experimentation and recitation. Roestiyah (2001) explains that demonstration is a way of teaching where a teacher instructor / team shows, showing a process according to Roestiyah (2001) an experimental method is a way of teaching, where students conduct an experiment about something, observe the process and write the results of the experiment, then The observations are conveyed to the class and evaluated by the teacher. Soekartawi (1995) defines that the recitation method is often referred to as the assignment method which is a method where students are given special assignments outside the learning hours. With this theory also applies the exploration of chain scissors in creating creative and innovative works so that the objectives are achieved to the maximum, then some of the methods used are:

1. Lecture method, used to convey material that is theoretical

2. Demonstration method, used to show various examples related to paper

3. Experiment method is the most important part because this method will provideexperience about the exploitation of editing experience

4.Method of recitation or assignment: used to strengthen mastery in creating creative and innovative work by expressing various techniques in editing.

\section{DISCUSSION}

Participants who took part in community service were 16 people consisting of principals and teachers in kindergartens in the District of Sunggai Limau Padang Pariaman

The results of the training at the first stage of the resource persons provided an explanation with power points, the teacher practiced making the basic first, namely cutting geometric shapes such as circles and oval shapes with colored origami paper on a white paper foundation, the results obtained were good in editing, but attached to paper has not yet been able to compile chain cuts in composition in art elements. In the second stage, the resource person gave the assignment again in a free form but in the early childhood curriculum study that was on the theme. Then the results we appreciate the participant's work. On the second day the resource person gave training on chain cutouts in the form of themes which became a story to the anatomy children. There is a theme that makes the school environment. Which consists of objects ranging from fences, trees, grass, flowers, kindergarten children who are holding hands, there is a school house. In accordance with the purpose of community service, especially Anugrah Sayang Ibu Kindergarten, which is to help kindergarten teachers to: (1) understand the principles and process of design development to be applied to various forms of paper according to the imagination of the participants, connected with themes that are in kindergarten, so that the design of the drawing becomes varied, (2) developing the design of images on coated paper folds (3) developing layered paper cutting skills.

These three objectives are interrelated, the purpose of the first point is an understanding of the process and requirements for making and developing a design, while the second point of purpose is the application of understanding into a product of economic value from the goal in the first point. This goal can be achieved well, in terms of understanding kindergarten teachers can already understand the understanding and principles of cutting. Then the materials and tools used
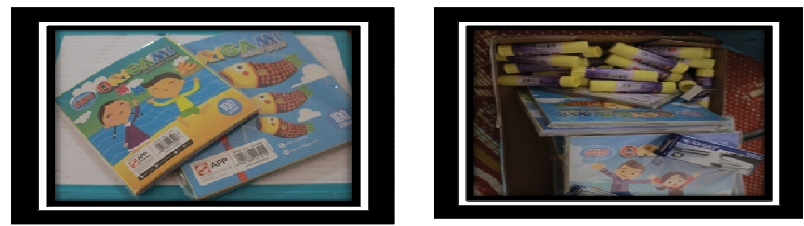

Figure 2. paper, glue, tongs

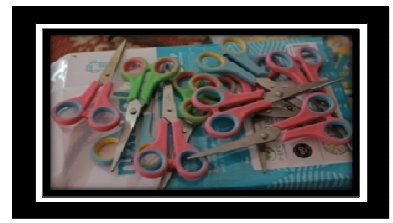

Figure 3. Scissors tool

As for the theoretical resource persons explained in advance with the theory of Law No. 20 th 2003. National education system article 1 paragraph 14 that Early Childhood Education (PAUD) is education that provides education services to early age at the age range of 0-6 years. Educators must be able to provide professional services to Children of Early Childhood (AUD) in order to lay the foundation towards the development of attitudes, knowledge, and skills, must be able to adjust to the environment. AUD Development: religious, social, emotional, language, cognitive, motor and artistic values.

One aspect of development that must be developed in kindergarten (TK) is the aspect of art, namely fine arts. Fine art is divided into two types, namely twodimensional, and three-dimensional art which is closely related to beauty: drawing, printing, meronce, shaping, folding, sticking, cutting in various creations. To develop the ability of fine arts in children as well as possible through fun activities. to develop the kindergarten teacher's creativity with the art of chain editing. 
The purpose 1) To be able to apply a variety of preparations to process the imagination and imagination in the right hemisphere. 2) to be able to develop fine motor skills of children. 3) For the learning needs of beautiful serial paper cutting works that have artistic value. 4) To be able to become an entrepreneur. 5) To be able to develop children's creativity because chain editing is related to fine arts and creativity.

The trainer explains that, a) this origami paper is in the shape of a rectangular cube printed on a blackboard, b) origami paper is folded in half, c) origami paper is cut into two parts, d) origami paper that is taken in one part then folded into four folds, e) make design drawings in accordance with the theme with a pencil, f) then scissors, g) paper folds that have been made drawings and scissors and stay certain material, so as not interrupted, h) open the paper fold and see the results.

At the beginning of editing the trainer taught how to fold paper with an archetypal model, such as an oval motif, then gradually extended into a tree, then developed into a human motif that is children and they each vary the shape he made according to his wishes

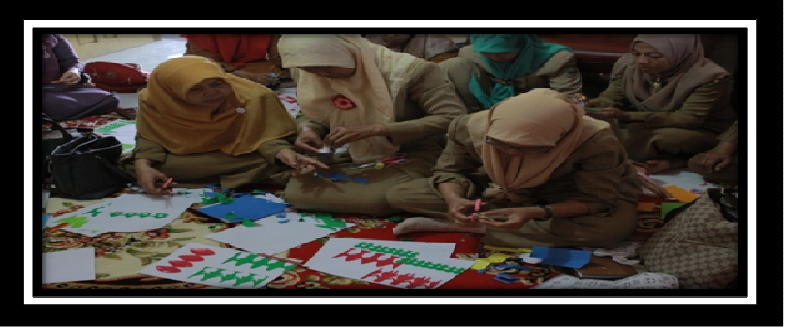

Figure 4. Participants practicing chain cutouts

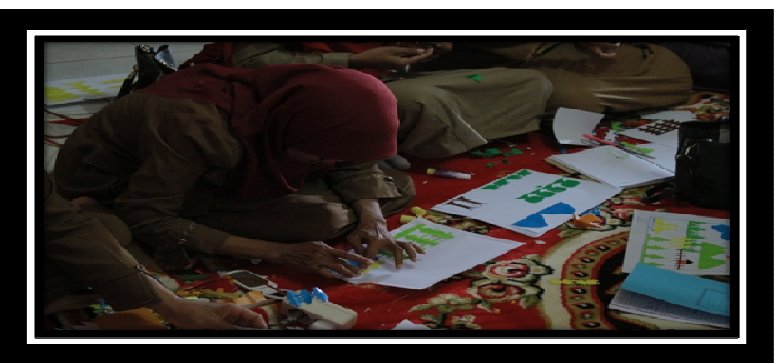

Figure 5. Participants taping the results of a chain scissor on the HVS paper

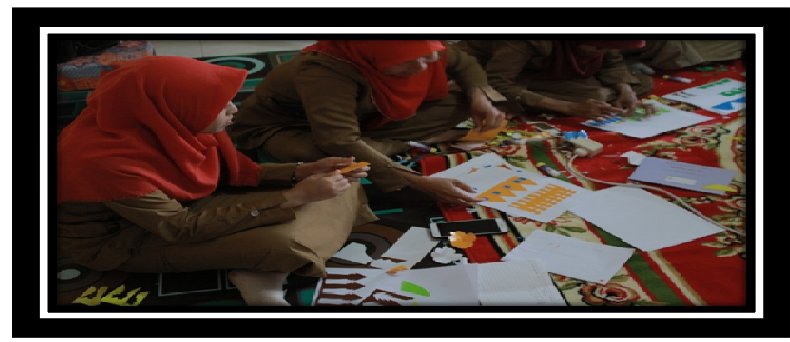

Figure 6. Participants are absorbed in the work they make

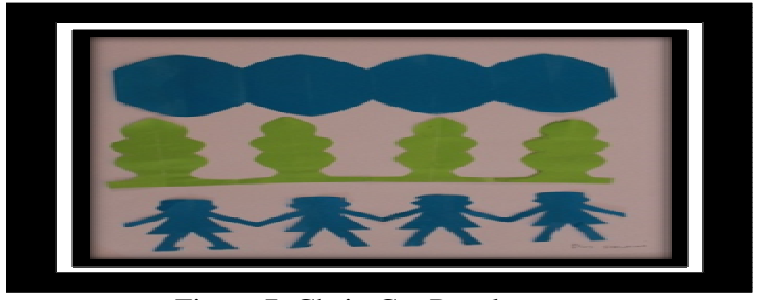

Figure 7. Chain Cut Results

From the work of the participants pretty good:

1. The participants enthusiastically watched him the trainer was giving him the cutting technique.

2. Participants can already edit the chain according to the themes in kindergarten such as the theme of themselves, the environment of fences, plants, and others

3. Participants can choose the paper that they want.

4. Participants can choose freely the theme that they made, even though the theme is the same but the object is different.

From the analysis found in fine arts education on the elements that are found.

1. Folding paper is not neat.

2. When cutting the object image that was designed it was cut off.

3. Placing an unbalanced object (composition).

4. Set the paper edge is not organized.

5. Can not put the dominant color in its place

\section{In the second activity}

After the trainer appreciates and evaluates the work the participants inform the specifics or focus on an interesting theme in the chain cutouts they are happy and serious. The work of the participants can be seen in the image below.
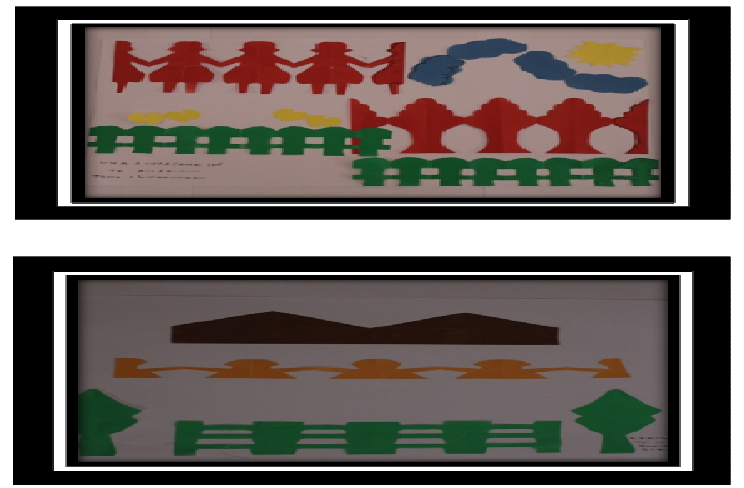

Figure $8 \& 9$. Results of a chain cut of self and environment

From the above motif we can see the left side of the red motif of the girl holding hands so this can be a theme of self and environment. If we pay attention to girls who cross hands, it means they are socially well. So chain cuttings can be concluded to yourself not only painting with crayons can also be done with chain cuttings meaning 
paper that is doubled folded and then cut once has become a number of motives.

To the right of the amoeba motif, which is a blue sky symbol attached to white paper, indicates the clouds and yellow symbolizes the sun. Then you can see that there is a blue, red fence making cutouts beautiful and making attractive patches and can be used as a theme.

In the cutout above depicts the title of the scene whose object consists of mountains, trees and fences. The object of the tree was chained and then developed into a creative. The tree which was originally joined together and then broken up into separated objects makes a balanced composition and the fence makes a position in the middle of the tree. In the picture above it can be said that the chain cutouts can develop children's imagination through fine motor skills.

After being analyzed on the first day there was still a shortage of trainers doing training the next day at the second meeting, namely the trainer increasing the specific development of changing the background color with origami paper and the purpose of being able to find out from some fine art elements including lines, composition, color.

Studying about lines in cutting how participants cut in the form of straight lines, curved lines, slanted lines, zigzag lines, of course participants also use lines to draw, but making lines by way of cutting will be different in the process. It should be noted that emotions are cutting, that is, emotions and concentrations must be centered, meaning eye and hand coordination, the mind should not be dazed, it must be balanced if not, the lines we made earlier by cutting will be cut off, but in drawing with a pencil if one can be erased. So in this case patience is requested in the editing activity, if it will not harm the maker, the reality is that in the first meeting many participants will carry out the activity of cutting off objects, this is what was corrected in the second meeting.

At the base of the paper to paste the selected color in laying one color with another color must be dominant not the same object with the background, as well as combining the colors are also known, so that the work made is more interesting. Example as follows
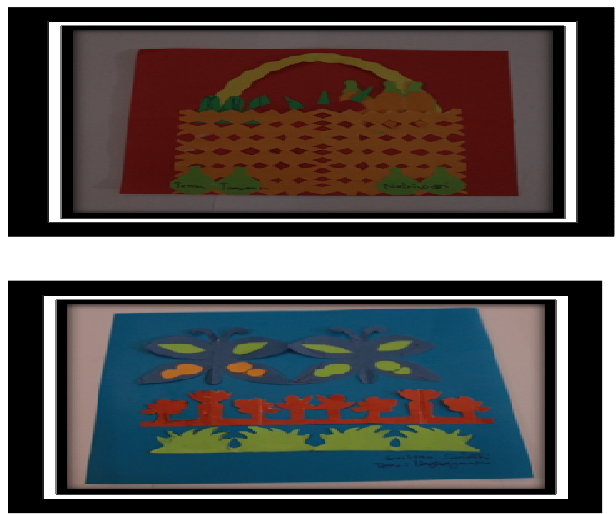

Figure $10 \& 11$. The work of cutting the chain with origami paper
In the picture above, the results of the chain scissors by combining the basic colors of paper with the colors of various objects can already place them and various motifs such as flowers, trees and butterflies.
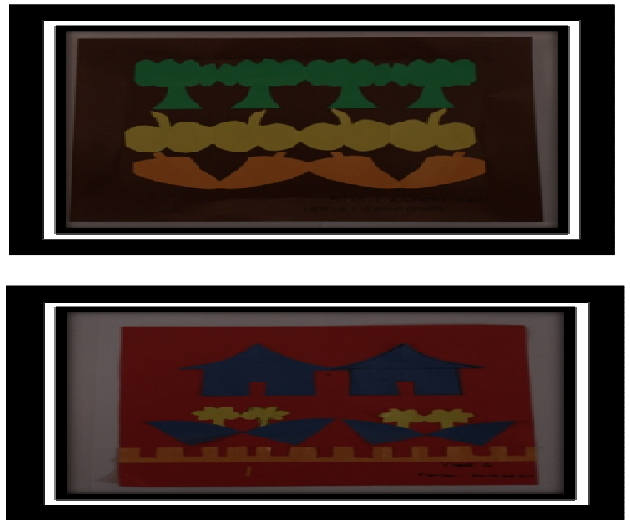

Figure $12 \& 13$. The work with the theme of the environment and plants

The results of the above work can be linked to the mathematical development of chain cutouts, the child will be able to count how many green plants the child makes through chain editing. Then how many apples from a chain cutout, and how many pieces of a cutout in an apple picture.

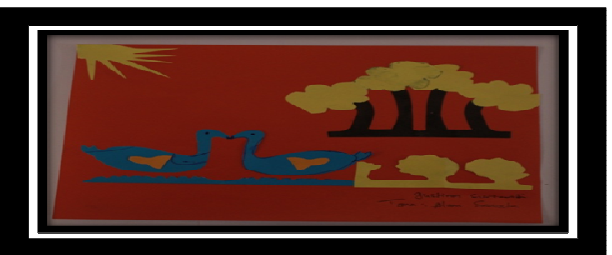

Figure 14. Results of animal theme chain cutouts

From the work of the participants, they were able to create creative chain linking objects with one another. Like a pair of ducks swimming, there are flowers, and there are plants behind them, and there is a sun shining.

From the discussion adjusted to the problems and target outcomes

1. The Sungai Limau Kindergarten teachers have never received chain editing training as paper material to develop learning materials for motor development and fine arts in kindergarten.

2. Material from paper that has been used to, usually only learn normal cutting like cutting objects with only one pattern. But by cutting chain can be the result of multiple clippings that are coupled.

3. Mastery and application of learning materials to develop motor and fine art in kindergarten with target outcomes

a. Improved understanding by kindergarten teachers in Sungai Limau District Padang Pariman. 
b. Products in the form of fine art from paper material each participant edited a chain producing three models.

\section{CONCLUSION AND SUGGESTION}

Departing from the fact that a community service plan was born, it could produce works with the identity of the absence of activities such as cutting a chain at the Kindergarten sub-district of Padang Pariaman river used for learning in kindergarten. As a material of paper that is widely used paper to fold, and stick to it. For that learning chain editing can develop creativity for kindergartens. In this case the paper is folded by multiplying folds, the drawing plan is designed with a pencil, cut out, when cutting, leaving some paper uninterrupted to use so that the paper does not separate from one another. After finishing editing the object remains. Like a chain picture. After getting the training the participants were tried out by kindergarten children who took part in training ranging from various kinds of paper, knowing to combine the colors of objects with background colors, how to draw objects they liked and then cut out on paper folds, they were very happy doing chain editing activities as learning material in kindergarten.

\section{REFERENCES}

[1] Chandra Mohanty, Bijo. 2018. Natural Dyeing Process of India, India: Sarabhai Foundation, Ahmamedabad, India.
[2] Greshoff.2009. Niuw Plantkundig Woordenboek Voor Indie, Druk Van J.H. De Bussy Amsterdam.

[3] Hoop, Van Der. 2016. Indonesiche Siermotieven. Koninlijk Batviaaash Genootschap Van Kusten En Wetenschappen.

[4] Medicinal Plans of East and Southeast Asia, Massachusetts Institute of Technology Press, Cambridge USA.

[5] Natural Dye Of Japan, t.Japan Tsuneo Yoshioka, Toshiba International Foundation.

[6] Pujianti, Yuli. 2012 Developing Self-Concepts Through Role Playing, Journal of Early Childhood Education Vol 6, No 2 (2012): Journal of Early Childhood Education, Publisher: PPS UNJ Jakarta.

[7] Rohidi Tjetjep Pohendi, 2015. Misikin Expression of Arts. Bandung: Nuance Foundation nuances.

[8] Susanto, Sewan.2015 Indonesian Batik Art Crafts, Yokyakarta: The Great Center for Batik and Yokyakarta Crafts.

[9] Trial Plantations of Non-Teak Wood Species in East Java. Japing, HW \& Oey Djoen Seng 